\title{
Skin Autofluorescence in Young Adult Offspring of Women with Type 1 Diabetes: A Cross-Sectional Case-Control Study
}

\author{
Cedric Korpijaakko (D) - Niko Wasenius · Kari Teramo • \\ Miira M. Klemetti · Hannu Kautiainen · Johan G. Eriksson • \\ Merja K. Laine
}

Received: November 26, 2020 / Accepted: January 9, 2021 / Published online: January 23, 2021

(c) The Author(s) 2021

\section{ABSTRACT}

Introduction: Offspring born to women with type 1 diabetes pregnancies have an elevated risk for early-onset obesity and type 2 diabetes compared with offspring born to women without diabetes. Skin autofluorescence (SAF) is a marker of accumulated advanced glycation end products (AGEs) and it has been shown to predict type 2 diabetes, cardiovascular disease, and mortality in the general population. The aim of this study was to evaluate whether maternal type 1 diabetes influences the SAF value in young adult offspring.

C. Korpijaakko $(\bowtie) \cdot$ N. Wasenius · H. Kautiainen . J. G. Eriksson · M. K. Laine

Department of General Practice and Primary Health Care, University of Helsinki and Helsinki University Hospital, Helsinki, Finland

e-mail: cedric.korpijaakko@helsinki.fi

N. Wasenius · H. Kautiainen · J. G. Eriksson ·

M. K. Laine

Folkhälsan Research Center, Helsinki, Finland

K. Teramo $\cdot$ M. M. Klemetti

Department of Obstetrics and Gynecology, Helsinki

University Hospital and University of Helsinki,

Helsinki, Finland

M. M. Klemetti

Department of Medical and Clinical Genetics,

University of Helsinki, Helsinki, Finland
Methods: This cross-sectional case-control study included 78 offspring of women with type 1 diabetes (cases) and 85 control participants (controls). All study participants, aged 18-23 years, were invited to participate in a clinical assessment including laboratory tests and questionnaires. SAF was assessed using the AGE reader from the dominant forearm of each participant.

Results: The mean SAF value did not differ between the cases (1.61 [standard deviation (SD) 0.37]) arbitrary units [AU]) and the controls (1.64 [SD 0.41] AU) $(p=0.69)$. After adjusting for glycated hemoglobin $A_{1 c}$, body fat percentage, smoking, and season the mean SAF value did not differ between the cases and the con-

\section{M. Klemetti}

Lunenfeld-Tanenbaum Research Institute, Sinai Health System, Toronto, Canada

\section{H. Kautiainen}

Primary Health Care Unit, Kuopio University Hospital, Kuopio, Finland

J. G. Eriksson

Human Potential Translational Research Programme and Department of Obstetrics and Gynecology, Yong Loo Lin School of Medicine, National University Singapore, Singapore, Singapore

\section{J. G. Eriksson}

Singapore Institute for Clinical Sciences (SICS), Agency for Science, Technology and Research (A*STAR), Singapore, Singapore 
trols $(p=0.49)$ but differed between men and women $(p=0.008)$, without any interaction observed $(p=0.78)$.

Conclusion: SAF values did not differ between the young adult offspring of women with type 1 diabetes and offspring born to mothers without diabetes. Surprisingly, young adult women showed higher SAF values than men in both case and control groups.

Keywords: Advanced glycation end products; Offspring; Sex; Skin autofluorescence; Type 1 diabetes pregnancy

\section{Key Summary Points}

\section{Why carry out this study?}

Offspring of type 1 diabetes pregnancies have an increased risk for early-onset obesity and type 2 diabetes compared to offspring of pregnancies without diabetes.

Skin autofluorescence (SAF), used as a marker of accumulated advanced glycation end products (AGEs), has been shown to predict type 2 diabetes, cardiovascular disease, and mortality in the general population.

The aim of this study was to evaluate whether maternal type 1 diabetes influences the SAF values in young adult offspring.

\section{What was learned from the study?}

In utero exposure to maternal type 1 diabetes does not appear to be associated with altered SAF values in young adult offspring.

Among young adults SAF may not be a feasible tool to capture the increased obesity and type 2 diabetes risk that offspring of type 1 diabetes pregnancies bear.

\section{DIGITAL FEATURES}

This article is published with digital features, including a summary slide, to facilitate understanding of the article. To view digital features for this article go to https://doi.org/10.6084/ m9.figshare.13547597.

\section{INTRODUCTION}

Advanced glycation end products (AGEs) are a group of heterogeneous molecules that are synthesized over the course of several years through a nonenzymatic reaction between reducing sugars and proteins [1]. The formation of AGEs is increased during metabolic stress; therefore, the gradual buildup of AGEs in longlived tissues (e.g., collagen) is theorized to be involved in the pathology of certain metabolic diseases, such as type 2 diabetes and chronic kidney disease, and aging [2, 3].

The non-invasive measurement of AGEs in dermal tissue, i.e., skin autofluorescence (SAF), relies on the fluorescent properties that some of the accumulated AGEs have [4]. As a promising tool for metabolic risk assessment, SAF is strongly associated with type 2 diabetes, diabetic complications, smoking, cardiovascular disease, aging, and overall mortality [4-6]. In addition to an associative relationship, SAF has been shown to predict incident type 2 diabetes, cardiovascular disease, and mortality in the general population $[6,7]$.

Since offspring of type 1 diabetes pregnancies are recognized as being more susceptible to early-onset obesity and type 2 diabetes [8-11], we hypothesized that hyperglycemia experienced during prenatal life would influence the glycemic memory of the young adult offspring, which could be registered by skin autofluorescence. The aim of this study was to investigate whether maternal type 1 diabetes influences the SAF value in young adult offspring. 


\section{METHODS}

\section{Research Design and Participants}

This is an observational cross-sectional case-control study performed in the Hospital District of Helsinki and Uusimaa, Finland. During the period between 1 January 1996 and 31 December 2000, all deliveries of women with type 1 diabetes from the Helsinki metropolitan area were centralized at the Department of Obstetrics and Gynecology, Helsinki University Hospital. Offspring of women with type 1 diabetes, from a singleton pregnancy born through elective caesarean section, composed the case participants of the study (cases, $n=238$ ). For each case subject, a control participant was obtained from the Finnish Medical Birth Register (http://www.thl.fi/en/statistics/parturients). The control participants (controls, $n=476$ ) were offspring of mothers without diabetes, from a singleton pregnancy, and born first or second after the delivery of the case participants in the Hospital District of Helsinki and Uusimaa, Finland.

All study participants, i.e., offspring of women with type 1 diabetes and their matched controls, were invited at the age of 18-23 years to a clinical study. Of the case group, $81(36 \%)$ participated, whereas, of the control group, 86 (20\%) participated. Three offspring of women with type 1 diabetes and one control participant who did not undergo the standard 2-h $75 \mathrm{~g}$ oral glucose tolerance test (OGTT) were excluded from the study cohort. Altogether, our study cohort consisted of 163 participants.

\section{Clinical Study}

The clinical study consisted of a clinical examination, laboratory tests, and questionnaires. All 163 participants were clinically evaluated. Weight and fat mass were measured by a bioimpedance body composition device (InBody 3.0, Biospace, Seoul, South Korea) in light indoor clothing without shoes and socks with an accuracy of $0.1 \mathrm{~kg}$. Height was measured with an accuracy of $0.1 \mathrm{~cm}$ (SECA Telescopic measuring rod, SHZ, cm INT). Body mass index (BMI) was calculated as body weight (kilograms) divided by height squared (meters squared). Fat percentage was calculated as fat mass (kilograms) divided by body weight (kilograms) converted to percentage. Blood pressure (BP) was measured from the right arm using a cuff size $22 \times 42 \mathrm{~cm}$ after at least 15 min of rest in a sitting position (Omron Intellisense M6 AC, Omron Healthcare Co. Ltd., Japan). BP was measured three times and the mean value was documented and applied in the calculations of pulse pressure $(\mathrm{PP}=$ systolic $\mathrm{BP}-$ diastolic $\mathrm{BP})$ and mean arterial pressure $(\mathrm{MAP}=$ diastolic $\mathrm{BP}+1 / 3 \times \mathrm{PP})$. The $\mathrm{BP}$ device also reported the heart rate which was documented. Skin autofluorescence was assessed with the AGE reader (AGE reader Type 214B00102, DiagnOptics, Groningen, the Netherlands) in a sitting position, from the inside of each participant's dominant forearm. Only healthy skin, excluding dermatological diseases and normal skin variations (such as birthmarks or tattoos), was eligible for SAF measurements. SAF is expressed as arbitrary units (AU), which is the ratio of emitted light intensity from the AGE reader (420-600 nm wavelength range) and the reflected excitation light intensity from the skin (300-420 nm wavelength range), multiplied by 100.

\section{Laboratory Analyses and Questionnaires}

Venous blood samples were taken after $10 \mathrm{~h}$ fasting for analyses of glycated hemoglobin $\mathrm{A}_{1 \mathrm{c}}$, total cholesterol, high-density lipoprotein cholesterol, low-density lipoprotein cholesterol, triglycerides, high-sensitivity C-reactive protein (hs-CRP), creatinine, and 25-hydroxy vitamin D. A 2-h $75 \mathrm{~g}$ OGTT was performed according to the WHO 1999 guidelines. Smoking habits and chronic diseases were assessed by validated self-administered questionnaires. Physical activity was measured with triaxial accelerometer (ActiGraph GT3X, Pensacola, FL, USA) for 7 days. The ActiGraph was worn on the non-dominant wrist and participants were instructed to wear the monitor for all activities except for swimming, bathing, or showering. The ActiLife software was used to determine 
wear time and to create 60-s epoch files. Each participant had to have at least 4 valid days ( $\geq 10 \mathrm{~h}$ of wear time/day) to be included in the analyses. A vector magnitude of three axes was calculated and total physical activity was reported in counts per minute. In Finland, the amount of sunlight varies by season and was considered by adjusting the main outcome according to the month of visit: winter (December, January, February), spring (March, April, May), summer (June, July, August), and autumn (September, October, November).

\section{Compliance with Ethics Guidelines}

This study was conducted in accordance with the Helsinki Declaration and was approved by the Ethics Committee of the Hospital District of Helsinki and Uusimaa (HUS/898/2017, 14 December 2017). All study participants provided written informed consent before any study procedures took place.

\section{Statistical Analyses}

Data are expressed as the mean and standard deviation (SD) and counts with percentages. The groups were compared with the $t$ test or permutation test, for continuous variables, and Pearson's chi-square test or Fisher's exact test, for categorical variables. Relationship between the groups and sex of SAF values were evaluated using bootstrap-type two-way analysis of covariance with glycated hemoglobin $\mathrm{A}_{1 \mathrm{c}}$, body fat percentage, smoking, and season as covariates. The bootstrap method is significantly helpful when the theoretical distribution of the test statistic is unknown or in the case of violation of the assumptions. The normality of the variables was evaluated graphically and by using the Shapiro-Wilk $W$ test. Stata 16.1 (StataCorp LP; College Station, TX, USA) statistical package was used for the analysis.

\section{RESULTS}

Table 1 shows the characteristics of all study participants divided into controls and cases. No difference was found in the mean SAF values between cases (1.61 [SD 0.37]) AU) and controls (1.64 [SD 0.41] AU) $(p=0.69)$.

Figure 1 shows the mean SAF values in the case and control groups divided into women and men. The $p$ value was 0.49 for comparison between the case and control group, $p=0.008$ for comparison between men and women, and no interaction was observed $(p=0.78)$, all after adjusting for glycated hemoglobin $\mathrm{A}_{1 \mathrm{c}}$, body fat percentage, smoking, and season.

\section{DISCUSSION}

We observed no differences in SAF values between young adult offspring of type 1 diabetes pregnancies and non-diabetic pregnancies. However, we found a sex difference in SAF values between men and women. To the best of our knowledge, this is the first study to address the relationship between SAF values, used as a marker of AGEs, among young adult offspring of type 1 diabetes pregnancies.

Offspring of type 1 diabetes pregnancies are more susceptible to early-onset obesity and type 2 diabetes [8-11], the latter being strongly associated with elevated SAF values [4-6]. Contrary to our hypothesis, we did not detect any association between maternal type 1 diabetes status and offspring SAF values in early adulthood. Lack of association could be explained by the fact that our study cohort was relatively healthy and consisted only of young adults. It is well established that accumulation of AGEs is an age-dependent process, which is influenced by many health-related factors such as oxidative stress, hyperglycemia, and impaired glomerular filtration rate [1-3]. Nevertheless, we observed no significant difference regarding glycated hemoglobin $\mathrm{A}_{1 \mathrm{c}}$ levels or glomerular filtration rate in our study cohort. Furthermore, according to several study observations smokers have higher SAF values in comparison to non-smokers [5, 12-15]; however, smoking among our study participants was too scarce to allow any further analyses.

We observed a sex difference in SAF values between men and women. Our study findings support previous findings that women have 
Table 1 Clinical characteristics of study participants divided into offspring of women with type 1 diabetes (cases) and offspring of women without diabetes (controls)

\begin{tabular}{|c|c|c|c|}
\hline & $\begin{array}{l}\text { Offspring of women without } \\
\text { diabetes (controls), } N=85\end{array}$ & $\begin{array}{l}\text { Offspring of women with type } 1 \\
\text { diabetes (cases), } N=78\end{array}$ & $p$ value \\
\hline Women, $n(\%)$ & $56(66)$ & $51(65)$ & 0.95 \\
\hline Age, years, mean $(\mathrm{SD})$ & $20.6(1.6)$ & $20.5(1.6)$ & 0.66 \\
\hline Smoking, $n(\%)$ & & & 0.34 \\
\hline No & $62(73)$ & $63(81)$ & \\
\hline Occasionally & $12(14)$ & $10(13)$ & \\
\hline Current & $11(13)$ & $5(6)$ & \\
\hline Body mass index, $\mathrm{kg} / \mathrm{m}^{2}$, mean $(\mathrm{SD})$ & $24.4(5.3)$ & $24.5(4.9)$ & 0.84 \\
\hline \multicolumn{4}{|l|}{ Body fat percentage (\%), mean (SD) } \\
\hline Women & $30.4(9.5)$ & $33.0(7.7)$ & 0.13 \\
\hline Men & $18.4(8.0)$ & $18.9(10.5)$ & 0.84 \\
\hline \multicolumn{4}{|l|}{ Blood pressure, mmHg, mean (SD) } \\
\hline Systolic & $119(11)$ & $117(12)$ & 0.29 \\
\hline Diastolic & $74(7)$ & $74(9)$ & 0.75 \\
\hline $\begin{array}{l}\text { Mean arterial pressure, } \mathrm{mmHg} \text {, mean } \\
\quad(\mathrm{SD})\end{array}$ & $89(7)$ & $88(9)$ & 0.50 \\
\hline Pulse pressure, $\mathrm{mmHg}$, mean (SD) & $45(8)$ & $43(9)$ & 0.29 \\
\hline Pulse rate, /min, mean $(\mathrm{SD})$ & $76(12)$ & $75(12)$ & 0.66 \\
\hline \multicolumn{4}{|l|}{ Glucose, $\mathrm{mmol} / \mathrm{L}$, mean $(\mathrm{SD})$} \\
\hline $0 \mathrm{~h}$ & $5.40(0.42)$ & $5.39(0.42)$ & 0.95 \\
\hline $2 \mathrm{~h}$ & $5.67(1.48)$ & $5.83(1.62)$ & 0.51 \\
\hline $\begin{array}{l}\text { Glycated hemoglobin } A_{1 c}, \mathrm{mmol} / \mathrm{mol} \text {, } \\
\text { mean }(S D)\end{array}$ & $32.6(2.2)$ & $32.8(2.7)$ & 0.62 \\
\hline \multicolumn{4}{|c|}{ Skin autofluorescence (SAF), arbitrary units (AU), mean (SD) } \\
\hline All & $1.61(0.37)$ & $1.64(0.41)$ & 0.69 \\
\hline Women & $1.67(0.42)$ & $1.70(0.47)$ & 0.72 \\
\hline Men & $1.50(0.22)$ & $1.51(0.22)$ & 0.81 \\
\hline Fasting insulin, mU/L, mean (SD) & $10.9(7.0)$ & $11.2(9.2)$ & 0.80 \\
\hline $\begin{array}{l}\text { Homeostatic model assessment } \\
\text { (Homa-IR), mmol/L, mean (SD) }\end{array}$ & $2.65(1.87)$ & $2.75(2.38)$ & 0.75 \\
\hline Total cholesterol, mmol/L, mean (SD) & $4.31(0.65)$ & $4.38(0.74)$ & 0.58 \\
\hline $\begin{array}{l}\text { Low-density lipoprotein cholesterol, } \\
\mathrm{mmol} / \mathrm{L} \text {, mean }(\mathrm{SD})\end{array}$ & $2.56(0.66)$ & $2.58(0.70)$ & 0.86 \\
\hline
\end{tabular}


Table 1 continued

\section{Offspring of women without}

diabetes (controls), $N=85$
Offspring of women with type $1 \quad p$ value diabetes (cases), $N=78$

High-density lipoprotein cholesterol, mmol/L, mean (SD)

$\begin{array}{ll}\text { Women } & 2.70(0.63) \\ \text { Men } & 2.49(0.66)\end{array}$

$2.47(0.68)$

0.19

Men

$2.49(0.66)$

$2.64(0.71)$

0.26

Triglycerides, $\mathrm{mmol} / \mathrm{L}$, mean (SD)

\begin{tabular}{lccc} 
Women & $1.00(0.51)$ & $0.96(0.62)$ & 0.73 \\
Men & $0.94(0.35)$ & $0.85(0.33)$ & 0.35 \\
$\begin{array}{l}\text { High sensitivity C-reactive protein, } \\
\text { mg/L, mean (SD) }\end{array}$ & $3.04(5.36)$ & $2.73(5.09)$ & 0.70 \\
$\begin{array}{l}\text { Glomerular filtration rate, CKD-epi, } \\
\text { mL/min/1.73 m }{ }^{2} \text { mean (SD) }\end{array}$ & $117(14)$ & $122(12)$ & 0.019 \\
$\begin{array}{l}\text { 25-Hydroxy vitamin D, nmol/L, mean (SD) } \\
\text { Women }\end{array}$ & $82.6(32.4)$ & & \\
Men & $70.0(23.4)$ & $75.4(35.0)$ & 0.27 \\
Comorbidity, $n$ (\%) & $11(13)$ & $63.9(20.0)$ & 0.30 \\
Asthma & $7(8)$ & & \\
Atopy & $1(1)$ & $10(13)$ & 0.97 \\
Psoriasis & $11(13)$ & $11(14)$ & 0.21 \\
Neurologic diseases & $3(4)$ & 0.34 \\
Cardiovascular disease & $12(16)$ & 0.61 \\
Rheumatic diseases & $3(4)$ & $5(7)$ & 0.74 \\
Mental diseases & $19(22)$ & $0(0)$ & 0.25 \\
Inflammatory bowel disease & $3(4)$ & $13(17)$ & $7(9)$ \\
Total physical activity, counts/min, \\
mean (SD) \\
\hline
\end{tabular}

$S D$ standard deviation

higher SAF values than men $[15,16]$. In a study regarding SAF reference values in the Saudi population, Ahmad et al. found that Saudi women had significantly higher SAF values than men across all age groups. Ahmad et al. discussed whether vitamin D deficiency might underlie some of the documented sex differences [16]; yet, in our present study the participants entered laboratory assessment during all four seasons and no significant difference between the sexes and the study groups was discovered at different vitamin D levels. Furthermore, Mook-Kanamori et al. found that women had significantly higher SAF values independently of ethnicity and type 2 diabetes in the Qatar population [15]. Nevertheless, Klenovics et al. reported that women tended to have higher SAF values than men, albeit this 


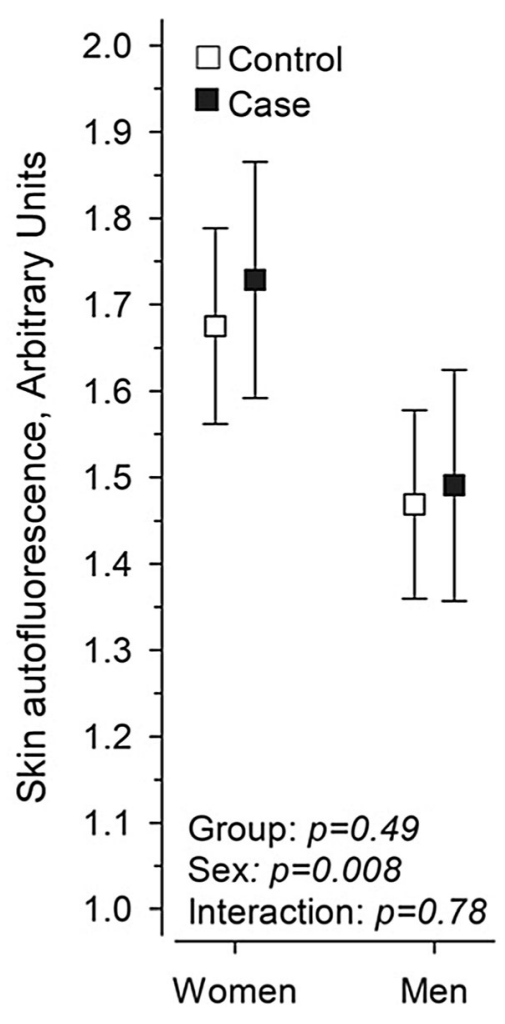

Fig. 1 Mean skin autofluorescence values in offspring of women with type 1 diabetes (cases) and of women without diabetes (controls) according to sex. Values are adjusted for glycated hemoglobin $A_{1 c}$, body fat percentage, smoking, and season. Whiskers shows $95 \%$ confidence intervals

was only statistically significant in 40- to 49-year-olds [13]. On the other hand, Koetsier et al. reported that only smoking women had higher SAF values than men [12]. However, there are conflicting results regarding sex and SAF values, since some studies have reported that SAF values are unaffected by sex [12-14].

One possible explanation could be due to a sex hormone-mediated effect [5]. Lutgers et al. reported that women under 56 years of age had higher SAF values than their male counterparts in the type 2 diabetes group; however, this significance was lost in the higher age groups [5]. Although we could not assess the estrogen concentration in our study population, this remains as an interesting theory for future studies regarding sex differences and SAF values.

We could find no difference in the conventional cardiovascular disease risk factors between offspring born to women with type 1 diabetes and offspring born to women without diabetes. In addition, no differences were found in comorbidities between the two groups of offspring.

Strengths and limitations of the study. One of the strengths of our study is the comprehensive data collected on study participants' cardiovascular disease health parameters. Further, all study participants were young adults, thus making the study population unique and homogeneous for the measurement of SAF values. As a result of the cross-sectional study design, we can only conclude that in utero exposure to type 1 diabetes does not appear to affect the SAF values in young adult offspring, without further commenting on causality. Moreover, there are a few limitations with the application of skin autofluorescence in cardiovascular disease risk assessment. Firstly, AGEs consist of a vast group of heterogenous protein modifications and the pathophysiological role of AGEs in age-related diseases still remains incompletely understood [1]. Secondly, some AGEs are not detectable with the AGE-reader and the effect of confounding factors, such as dermatologically fluorescent compounds or the use of skin cream, might interfere with the measurements $[3,4,17]$. Nevertheless, owing to its non-invasiveness, cost, and repeatability, skin autofluorescence may be a useful tool for individual metabolic risk assessment. Finally, although our results are interesting, they should be confirmed by studies with larger sample size.

\section{CONCLUSIONS}

We found that exposure to maternal type 1 diabetes is not associated with changes in the SAF values of young adult offspring. Furthermore, a sex difference in relation to SAF was observed. The usability of SAF in adult offspring of type 1 diabetes pregnancies warrants further research.

\section{ACKNOWLEDGEMENTS}

We thank the participants of the study. 
Funding. Finska Läkaresällskapet and the Hospital District of Helsinki and Uusimaa, Finland, were awarded a research grant for this study. The funding sources had no role for conducting the research, preparation or publication of the article.

Authorship. All named authors meet the International Committee of Medical Journal Editors criteria for authorship for this article, take responsibility for the integrity of the work as a whole, and have given their approval for this version to be published.

Authorship Contributions. Substantial contributions to conception and design: MKL, MMK, JGE, KT; Acquisition of data: MKL, MMK, JGE, NW; Data analysis: CK, HK, JGE, MKL; Interpretation of data: CK, $\mathrm{HK}, \mathrm{NW}, \mathrm{KT}, \mathrm{MMK}$, JGE, MKL; Drafting the article or revising it critically for important intellectual content: CK, HK, NW, KT, MMK, JGE, MKL; Final approval of the version to be published: $\mathrm{CK}, \mathrm{HK}, \mathrm{NW}, \mathrm{KT}$, MMK, JGE, MKL.

Disclosures. Cedric Korpijaakko, Niko Wasenius, Kari Teramo, Miira M. Klemetti, Hannu Kautiainen, Johan G. Eriksson, Merja K. Laine declare that they have no conflict of interest.

Compliance with Ethics Guidelines. This study was conducted in accordance with the Helsinki Declaration and was approved by the Ethics Committee of the Hospital District of Helsinki and Uusimaa (HUS/898/2017, 14 December 2017). All study participants provided written informed consent before any study procedures took place.

Data Availability. Data cannot be shared for both legal and ethical reasons.

Open Access. This article is licensed under a Creative Commons Attribution-NonCommercial 4.0 International License, which permits any non-commercial use, sharing, adaptation, distribution and reproduction in any medium or format, as long as you give appropriate credit to the original author(s) and the source, provide a link to the Creative Commons licence, and indicate if changes were made. The images or other third party material in this article are included in the article's Creative Commons licence, unless indicated otherwise in a credit line to the material. If material is not included in the article's Creative Commons licence and your intended use is not permitted by statutory regulation or exceeds the permitted use, you will need to obtain permission directly from the copyright holder. To view a copy of this licence, visit http://creativecommons.org/licenses/by$\mathrm{nc} / 4.0 /$.

\section{REFERENCES}

1. Chaudhuri J, Bains Y, Guha S, et al. The role of advanced glycation end products in aging and metabolic diseases: bridging association and causality. Cell Metab. 2018;28(3):337-352. https:// doi.org/10.1016/j.cmet.2018.08.014.

2. Nowotny K, Jung T, Hohn A, Weber D, Grune T. Advanced glycation end products and oxidative stress in type 2 diabetes mellitus. Biomolecules. 2015;5(1):194-222. biom 5010194 .

3. Rabbani N, Thornalley PJ. Advanced glycation end products in the pathogenesis of chronic kidney disease. Kidney Int. 2018;93(4):803-13.

4. Da Moura SC, Webb M, Waller H, Khunti K, Davies M. Skin autofluorescence, a non-invasive marker of advanced glycation end products: clinical relevance and limitations. Postgrad Med J. 2017;93(1099): 289-94. https://doi.org/10.1136/postgradmedj2016-134579.

5. Lutgers HL, Graaff R, Links TP, et al. Skin autofluorescence as a noninvasive marker of vascular damage in patients with type 2 diabetes. Diabetes Care. 2006;29(12):2654-9.

6. Gerrits EG, Lutgers HL, Kleefstra N, et al. Skin autofluorescence: a tool to identify type 2 diabetic patients at risk for developing microvascular complications. Diabetes Care. 2008;31(3):517-21.

7. van Waateringe RP, Fokkens BT, Slagter SN, et al. Skin autofluorescence predicts incident type 2 diabetes, cardiovascular disease and mortality in the general population. Diabetologia. 2019;62(2): 269-80. https://doi.org/10.1007/s00125-018-4769$\mathrm{x}$. 
8. Kawasaki M, Arata N, Miyazaki C, et al. Obesity and abnormal glucose tolerance in offspring of diabetic mothers: a systematic review and meta-analysis. PLoS One. 2018;13(1):e0190676. https://doi.org/10. 1371/journal.pone.0190676.

9. Pitchika A, Jolink M, Winkler C, et al. Associations of maternal type 1 diabetes with childhood adiposity and metabolic health in the offspring: a prospective cohort study. Diabetologia. 2018;61(11):2319-32. https://doi.org/10.1007/ s00125-018-4688-x.

10. Weiss PA, Scholz HS, Haas J, Tamussino KF, Seissler J, Borkenstein $\mathrm{MH}$. Long-term follow-up of infants of mothers with type 1 diabetes: evidence for hereditary and nonhereditary transmission of diabetes and precursors. Diabetes Care. 2000;23(7): 905-11. https://doi.org/10.2337/diacare.23.7.905.

11. Vlachová Z, Bytoft B, Knorr S, et al. Increased metabolic risk in adolescent offspring of mothers with type 1 diabetes: the EPICOM study. Diabetologia. 2015;58(7):1454-63. https://doi.org/10. 1007/s00125-015-3589-5.

12. Koetsier M, Lutgers HL, de Jonge C, Links TP, Smit AJ, Graaff R. Reference values of skin autofluorescence. Diabetes Technol Ther. 2010;12(5):399-403. https://doi.org/10.1089/dia.2009.0113.
13. Klenovics SK, Kollárová R, Hodosy J, Celec P, Šebeková K. Reference values of skin autofluorescence as an estimation of tissue accumulation of advanced glycation end products in a general slovak population. Diabet Med. 2014;31(5):581-5. https://doi. org/10.1111/dme.12326.

14. Yue X, Hu H, Koetsier M, Graaff R, Han C. Reference values for the Chinese population of skin autofluorescence as a marker of advanced glycation end products accumulated in tissue. Diabet Med. 2011;28(7):818-23. https://doi.org/10.1111/j.14645491.2010.03217.x.

15. Mook-Kanamori MJ, Selim MM, Takiddin AH, et al. Ethnic and gender differences in advanced glycation end products measured by skin auto-fluorescence. Dermatoendocrinol. 2013;5(2):325-30. https://doi.org/10.4161/derm.26046.

16. Ahmad MS, Damanhouri ZA, Kimhofer T, Mosli $\mathrm{HH}$, Holmes E. A new gender-specific model for skin autofluorescence risk stratification. Sci Rep. 2015;5: 10198. https://doi.org/10.1038/srep10198.

17. Noordzij MJ, Lefrandt JD, Graaff R, Smit AJ. Dermal factors influencing measurement of skin autofluorescence. Diabetes Technol Ther. 2011;13(2): 165-70. https://doi.org/10.1089/dia.2010.0123. 